\title{
SIDD - SCRUM ITERATION DRIVEN DEVELOPMENT: AN AGILE SOFTWARE DEVELOPMENT AND MANAGEMENT PROCESS BASED ON SCRUM
}

\author{
Tayse Virgulino Ribeiro ${ }^{1} \quad$ Cristina D’Ornelas Filipakis Souza ${ }^{2} \quad$ Heloise Acco Tives Leão $^{3}$ \\ ${ }^{1,2}$ Lutheran University Center of Palmas - CEULP/ULBRA, Palmas - TO - Brazil \\ ${ }^{3}$ Department of Computer Science - University of Brasília (UnB) - Brasília-DF, Brazil \\ E-mail: \{tayse1000,filipakis, heloise.acco\}@gmail.com
}

\begin{abstract}
Scrum Iteration Driven Development is an agile, Scrumbased process that allows the management and development of software, making possible an improvement in the software development process, with the objective of assisting in the management and planning of software projects. The proposal of Scrum Iteration Driven Development (SIDD) is to be an agile process capable of directing development and management activities. Therefore, considers the context of the company, to help them follow the principles of this process in its entirety, without the need for complementary techniques. Finally, to disseminate the results of the work, an interactive presentation area of the SIDD process was developed with information related to the software development and management process, with the intention of being a guide to assist the users in the project management process 1 .
\end{abstract}

Keywords - Software Engineering, Agile Methodology, Scrum, Development Process, SIDD.

\section{INTRODUCTION}

Pressman [3] states that software engineers should strive to produce and use techniques and tools to develop highquality systems. Currently, the reality for large and small companies is the difficulty to understand the concepts of Software Engineering tha leads to misuse of software development practices.

Therefore, this work emphasizes a specific agile software development methodology, called Scrum. According to Sabbagh [5], Scrum is an agile, simple and lightweight framework used to manage the development of complex products. Identifying it as a framework means that it is able

\footnotetext{
${ }^{1}$ DOI reference number: 10.18293/SEKE2018-102
}

to solve a problem in a particular domain, and to solve this problem, your applications needs to be working according to project standards.

In this way, the present work aims to create an agile process, allowing the development and management of software in an iterative way. This process is based on a qualitative and quantitative research carried out with 20 companies from the city of Palmas, Tocantins - Brazil, in April 2017 by Ribeiro [4], addressing the interviewees about the use of software development practices. This research aimed to identify the approach of the use and the evolution of the companies in the context of software development process, to obtain a better understanding of the use of agile practices. Therefore, to propose a software management and development process in order to provide improvement in the software development process.

Based on this, the problem that this paper seeks to solve is related to the creation of a Scrum-based agile process for software development and management in order to provide improvement in the software development process of companies. Raising as hypothesis, if there is an understanding of the company profile analysis and the approach to using Scrum, then it is possible to create a Scrum-based agile process for software development and management in order to provide improvement in the software development process.

Thus, the proposal to use the SIDD process has positive aspects in the aid of the administration of project management activities, such as the creation of specific artifacts that aid in the management and development of the software. However, the process tends to lose agility face other agile processes, because there is an addition of events and artifacts construction in its tasks. This addition is what introduces the management context to the process. 


\section{THEORETICAL FRAMEWORK}

After the "software crisis" in the mid-1990s, agile methodologies became known as methods of improving development processes. In the year 2001, an Agile Manifesto was written by Kent Beck and sixteen other software professionals. This manifesto generated twelve principles that explain the concept of agility in the area of software development. From that year, the term "Agile Methodologies" became popular in this field.

According to Sharma and Hasteer [6], in the world of software development industry, traditional software development has moved to the agile model over the years. In this field there are many methodologies, such as Scrum, Extreme Programming, Crystal, FDD (Feature-driven development), DSDM (Dynamic Systems Development Method, etc. The agile process developed in this work emerged as a technique to aid in software development.

Khmelevsky, Li and Madnick [2] complement that agile practices such as Scrum, which allow a better dynamic of concentration between the teams and an agile delivery, have become one of the easiest and most desirable techniques to work with. On the other hand, it should be noted that it is necessary to evaluate the type of project to which the technique will be applied, since the process may not be directly applicable.

The use of an agile process is directly related to the application environment and the approach type. Therefore, Srivastava, Bhardwaj and Saraswat [7] state that the use of an agile method has a different approach and perspective for each project.

\section{METHODOLOGY}

The composition of the work development methodology elaborated for design the SIDD process is shown in Figure 1. In the study phase of the theoretical reference was car-

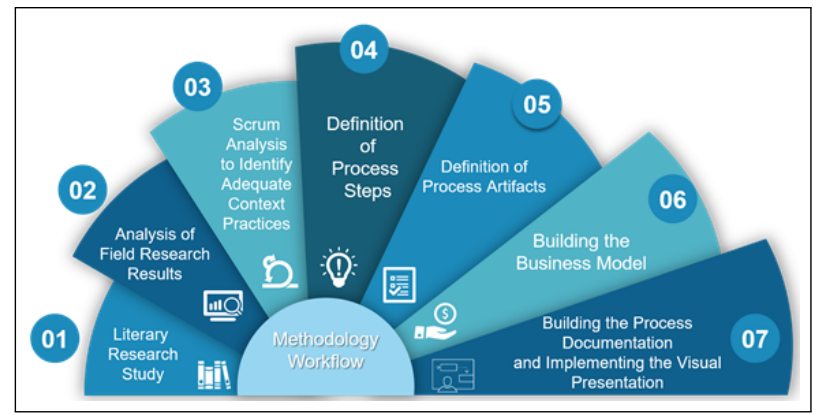

Figure 1. Methodology of the developed stages of the project.

ried out a study of the main concepts related to the use of agile development processes, as well as quality approaches to software processes. After that, a qualitative-quantitative research was carried out in 20 software development companies in Palmas-TO, Brazil in the year 2017. From the analysis of the results obtained in the research it was possible to start planning the business model, which is the third stage of the work methodology.

A business model was created for the process, in order to describe aspects related to the use of the management and development process in the job market. In this way, were verified the benefits that this process will provide for its customers, the resources necessary for its use to be possible and the way in which the communication with the client will be established.

After the construction of the business model, an analysis of the Scrum development process was carried out to identify suitable practices for the scenario. This analysis was carried out in order to understand the scenario of software development in private companies, with the purpose of defining a proposal for a software management and development process appropriate to the companies.

Faced with this, the definition of the steps of the SIDD Process was started with the purpose of presenting the definition of the workflow of the software development and management process that is developed in this work.

With the steps delineated, the definition of the artifacts was started, elucidating all the artifacts used for the composition of the process and presentation of the documentation. And finally, the visual representation of the SIDD process was created. In this phase the flow is presented in a graphical way, relating the roles to the stages in which they are involved.

\section{QUALI-QUANTITATIVE RESEARCH}

A qualitative-quantitative research was carried out in 20 software development companies in Palmas-TO, Brazil in the year 2017 with the objective of evaluating the evolution and needs of the utilization of development processes in the companies and agencies of this city. According to what was collected in the research, where it can be seen that seven companies did not adopt a specific software development practice, two adopted traditional development practices, while eleven adopted agile practices. In addition, $100 \%$ of companies that used agile practices used the Scrum development process as a basis, but with adaptations.

In some companies/agencies there was adaptations related to term and events that are approached in agile practices. Six of the companies, made adaptations of sprints and backlog times in project planning, changing the schedule, as they can not meet the deadline initially reported. One of these adaptations, for example, refers to the project progression meetings (Daily's - Scheduled Scrum Meetings). 
The adjustments made at the meetings were not specified. But the adaptations can be related to two points, which are: not holding meetings or holding meetings more consistently (e.g. a meeting per day period rather than at the end of the day). Some adaptations are not possible to identify, since the partial way of use was not informed and in other cases the responsible person was not able to respond. It is worth mentioning that all adaptations should be evaluated, since accession to a methodology basically means following its principles.

Based on this, it is necessary to take some aspects into account before adopting a development practice. The company / organization must make a diagnosis in the sector, to verify how its management style behaves and if they have trained individuals. After identifying these characteristics, the entire industry and the company must commit to the plans that will be carried out, since this is a significant influence. According to the theoretical reference, it is possible to observe some important criteria when adopting a software development practice. According to Awad [1] and Stoica, et al. [8], there are a number of factors influencing the traditional methodology, such as: methodology approach; maturity of the company/body and team; team composition; level of project knowledge; perspective of project change, communication, culture, documentation and the project's return on investment.

Thus, a proposal for a new agile software development process capable of directing the development and management activities, besides taking into account the context of the company, can contribute for the companies follow the processes in its entirety, without the necessity for complementary techniques.

\section{SCRUM ITERATION DRIVEN DEVEL- OPMENT}

The process of development and management of SIDD software was obtained through the case study carried out, in which the presentation flow was created with the aim of facilitating the presentation of the software development and management process. Figure 2 presents, graphically, the workflow of the process developed in this work.

The division of the process takes place in the accomplishment of the events, in the construction of the artifacts and in the participation of their respective roles. The SIDD process consists of the following events: Planning Meeting, Sprint Planning, Planning Poker (optional), Sprint, Daily SIDD and Sprint Review.

In the execution of these events the following artifacts are generated: Project Model Canvas, Product Backlog, Sprint Backlog, Object Model(optional), Sequence Diagram (optional), Testing Session, Definition of Done and Product Increment.

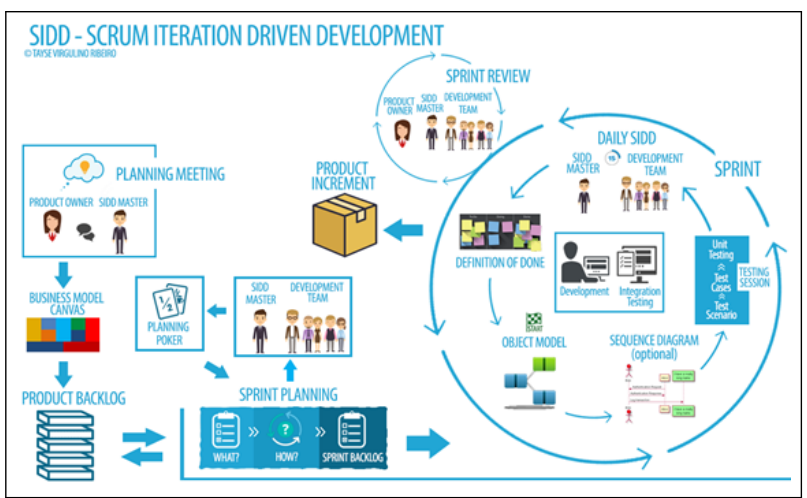

Figure 2. Structure of the Process.

Thereby and to carry out the SIDD cycle, the participation of SIDD Team is required. This team consists of the following roles: Product Owner, SIDD Master and Development Team. These roles aim to achieve results with quality and agility, in a proactive and collaborative way. The performance of a role is directly related to a set of executed events and their developed artifacts.

The participation of the Product Owner in the SIDD process begins in Planning Meeting. This meeting discusses the need of the customer and what will be generated of value. With this, the Product Owner and SIDD Master work to define the Project Model Canvas. Based on this, the items that make up the Product Backlog are defined. Finally, it participates in conjunction with the SIDD Master and the Development Team in the performance of the Sprint Review activity, assisting in the evaluation regarding the fulfillment of the Sprint objective, characterizing the delivery of the product. SIDD Master is responsible for leading and facilitating the work of the Development Team in order to promote organizational skills, communication and continuous improvement in the development process. SIDD Master is one of the only roles that is present all the time in the product design process because it aims to monitor the progress of all activities and keep the project always aligned with the needs of the Product Owner.

Its participation begins in the Planning Meeting. After that, the Product Owner and SIDD Master work to define the Project Model Canvas. As a consequence, the items that make up the Product Backlog are defined. In addition, Sprint Backlog planning is done in the Sprint Planning event. In the act of this planning the SIDD Master and the Development Team are also performing the Planning Poker. After that, at the execution of Sprint, the Development Team contributes in the accomplishment of the daily meeting, known like Daily SIDD. During the execution of Sprint, SIDD Master participates in assisting and leading the Development Team in the construction of the artifacts that aid in the development of the product, such as: Object 
Model(optional), Sequence Diagram (Optional), Test Session, Definition of Done and Product Increment.

The Development Team is responsible for developing the product. Therefore, the team should contemplate some characteristics, such as: specialty in the field, self-organization, focus, motivation, discipline, agility and teamwork. The Development Team begins its participation in the Sprint Planning event. In this event, you define what will be done from the beginning of the project execution. At the time of this planning, the team also conducts Planning Poker. After that, in the execution of Sprint the Development Team contributes in the accomplishment of the Daily SIDD. During the execution of Sprint, the team participates in the generation of the same artifacts that aid in product development.

To disseminate the results of the work, an interative presentation area of the SIDD process was developed, with information related to the software development and management process, which can be accessed through the following link http://metodologiasidd.com.br/. This area was presented according to the structure of the process, which is performed in the accomplishment of the events, in the construction of the artifacts and in the participation of their respective roles. The development of the site was mainly aimed at the development of the process guide area (http://metodologiasidd.com.br/guide.html), in which it is possible to obtain the orientation of the Scrum Iteration Driven Development process, presenting the main areas of the process, which are: events, artifacts, and roles.

\section{CONCLUSION}

In the analysis of the results of the qualitativequantitative research carried out by Ribeiro [4], it was possible to observe that the companies that worked with the practice of agile development did not necessarily meet all the principles of a methodology, since much of its use was made in a partial way. Besides that, it was noted that the use of Scrum as a methodology was standard in the software development companies in the region. Thus, this research had the goal of questioning respondents on the use of software development practices analysis of the information obtained.

In this way, the proposal of a new agile process capable of directing the activities of development and management, in addition to taking into account the company context, can assist companies to follow the principles of this process in its entirety, without need for complementary techniques. Based on this, the objective of this study was to provide an improvement in the software development process of enterprises. Therefore, in addition to explaining the concepts of agile methodology and the steps of the process Scrum, this work consisted in modeling an agile process based on Scrum that allows software management and development.
From this, the Scrum Iteration Driven Development, an agile process based on Scrum, was developed, which allows the management and development of software, making possible an improvement in the software development process, with the objective of assisting in the management and planning of software projects.

Therefore, the use of the SIDD is beneficial in assisting the management of project management activities, such as creating specific artifacts that assist the management and development of software. However, the process tends to lose agility face other agile processes, because there is an addition of events and artifacts construction in its tasks. This addition is what introduces the management context to the process.

\section{References}

[1] M. Awad. A comparison between agile and traditional software development methodologies, this report is submitted as partial fulfillment of the requirements for the honours. In The University of Western Australia. Citeseer, 2005.

[2] Y. Khmelevsky, X. Li, and S. Madnick. Software development using agile and scrum in distributed teams. In $2017 \mathrm{An}$ nual IEEE International Systems Conference (SysCon), pages 1-4, April 2017.

[3] R. Pressman. Engenharia de software: uma abordagem profissional [internet], 2011.

[4] T. V. Ribeiro. Quantitative Research on Software Development Processes Used by Companies in Palmas-TO. 2017.

[5] R. Sabbagh. Scrum: Gestão ágil para projetos de sucesso. Editora Casa do Código, 2014.

[6] S. Sharma and N. Hasteer. A comprehensive study on state of scrum development. In 2016 International Conference on Computing, Communication and Automation (ICCCA), pages 867-872, April 2016.

[7] A. Srivastava, S. Bhardwaj, and S. Saraswat. Scrum model for agile methodology. In 2017 International Conference on Computing, Communication and Automation (ICCCA), pages 864-869, May 2017.

[8] M. Stoica, M. Mircea, and B. Ghilic-Micu. Software development: Agile vs. traditional. Informatica Economica, 17(4):64, 2013. 